\title{
Examination of the Pathogenesis of Diabetic Nephropathy in OLETF Rats
}

\author{
Kazuya KAWANO, Shigehito MORI, Tsukasa HIRASHIMA, Zhi-Wei MAN and Takashi NATORI \\ Tokushima Research Institute, Otsuka Pharmaceutical Co.,Ltd., 463-10 Kagasuno, Kawauchi-cho, Tokushima 771-0192, Japan
}

(Received 28 May 1999/Accepted 24 July 1999)

ABSTRACT. We conducted protein loading to examine the progression and pathogenesis of diabetic nephropathy. For this experiment, male OLETF, LETO, F344 and BN rats were used. This experiment was performed on rats between 5 and 30 weeks of age. Examination parameters included body weight, food intake, oral glucose tolerance test (OGTT), urinary protein level (UP), urinary albumin level (UA), glomerular filtration rate (GFR), kidney weights, light microscopy (LM) and electron microscopy (EM). In the protein-loaded OLETF group, the UP level was markedly increased 20 weeks or more after birth. In OLETF control group, GFR were higher than those in other strains. Glomerular hypertrophy and kidney weights were markedly increased in protein-loaded groups in OLETF rats. Thirty weeks after birth, EM showed that the number of polyethyleneimine (PEI) of the glomerular basement membrane (GBM) in protein-loaded OLETF group was significantly decreased compared to that in control group. These changes in OLETF rats were more marked in the proteinloaded group than those in the control group. LM showed that the number of exudative lesions with fibrin-cap in the protein-loaded OLETF group was significantly increased than those in control group. In OLETF rats, protein loading caused deterioration of nephropathy at 30 weeks of age. Therefore, it was demonstrated that not only blood sugar control but also protein intake factors play important roles in the deterioration of nephropathy in OLETF rats.-KEY wORDS: diabetes, nephropathy, OLETF, protein, rat.

J. Vet. Med. Sci. 61(11): 1219-1228, 1999

In advanced countries, diabetic nephropathy mainly causes terminal renal failure. In Japan, patients with diabetic nephropathy comprise about $30 \%$ of patients receiving dialysis. The ratio has been increasing year by year. In 20 to $40 \%$ of patients with insulin-dependent diabetes mellitus (IDDM), nephropathy causes terminal renal failure. Even among patients with non-insulin-dependent diabetes mellitus (NIDDM), who comprise approximately $99 \%$ of diabetics in Japan, 10 to $20 \%$ of patients develop terminal renal failure. However, the etiology of these complications remains to be clarified in many aspects.

The OLETF rat is a new animal model of human NIDDM that has been established from an outbred Long-Evans strain from Charles River Canada [5]. The OLETF rat develops a diabetic syndrome in nearly $100 \%$ of male rats at 25 weeks of age. The OLETF rats exhibit hyperglycemia and hyperinsulinemia in the early phase of the disease as a result of islet cell hyperplasia and peripheral insulin-resistance [4$5,12]$. As age proceeds, the rat eventually develops hypoinsulinemia as a result of deterioration of the islets B cells. At 40 weeks of age, exudative changes occur in kidneys, which closely resemble human NIDDM [5]. The LETO rat was obtained by different original mating from those for OLETF rats, but both strains originated from the same colony of Long-Evans rats. The LETO rat has not shown the diabetic syndrome.

It has been reported that deterioration of diabetic nephropathy depends on the duration of diabetes and success or failure in controlling blood sugar. Based on this concept, we performed sucrose loading in OLETF rats demonstrating exudative lesions with fibrin-cap in the kidney glomerulus, which resembled that in humans, to exacerbate diabetic conditions and cause deterioration of nephropathy. As a result, exacerbation of diabetes was observed, while nephropathy did not differ from that in untreated OLETF rats $[8,9]$. As a factor in this finding, food intake and protein intakes were decreased because sucrose-loaded rats liked to ingest sucrose. The decrease in protein intake may have influenced deterioration of nephropathy. Furthermore, in humans, it has been reported that a protein-restricted diet is effective in treating diabetic nephropathy. Therefore, we speculated that there might be an association between deterioration of diabetic nephropathy and protein intake.

In this study, we performed protein loading in OLETF rats, and examined the involvement of protein in deterioration of diabetic nephropathy.

\section{MATERIALS AND METHODS}

\section{Establishment of experimental groups}

We used male OLETF and LETO rats bred at the Tokushima Research Institute of Otsuka Pharmaceutical Co., Ltd. as well as F344 and BN rats purchased from Charles River Japan Inc. (Yokohama). In all strains, we established control groups in which standard chow (CRF-1; Oriental Yeast Co., Ltd., containing $23 \%$ crude protein) was given and $40 \%$ protein-loaded groups $(40 \%$ crude protein was contained in food). The food composition was shown in Table 1. Eight animals were assigned to each group. This experiment was conducted in rats between 5 and 30 weeks of age. Animals were acclimated in the specific pathogenfree (SPF) room under the following conditions; temperature, $23 \pm 2{ }^{\circ} \mathrm{C}$; humidity, $60 \pm 10 \%$; and lighting cycle, $12 \mathrm{hr}$ (7:00 a.m. to 7:00 p.m.). Tap water was given ad libitum.

Measurement parameters

Body weight and food intake: Body weight and food intakes were measured at 2-week intervals between 5 and 
Table 1. Food composition in each groups

\begin{tabular}{lcc}
\hline Composition & Protein-loaded Group & Control group \\
\hline Crude protein (\%) & 40.5 & 23.1 \\
Crude fat (\%) & 4.2 & 5.9 \\
Soluble nitrogen- & 37.4 & 53.5 \\
free substance (\%) & 351 & 360 \\
Total calories (cal) & 350 \\
\hline
\end{tabular}

30 weeks of age.

Oral glucose tolerance test (OGTT): OGTT was performed 26 weeks after birth. For OGTT, $0.4 \mathrm{ml} / 100 \mathrm{~g}$ body weight $(2 \mathrm{~g} / \mathrm{kg})$ of $50 \%$ glucose solution was orally administered after a 16-hr fast. Blood was collected through the tail artery before and 30, 60, 90 and $120 \mathrm{~min}$ after glucose administration. Plasma glucose and insulin levels were measured using a Wako glucose B test (Wako Pure Chemical Industry Co., Ltd.) and kit for measuring insulin (Morinaga Bioscience Institute Co., Ltd.), respectively.

Urinary protein and albumin levels: After rats were fasted for $24 \mathrm{hr}$ in metabolic cages, urine specimens were collected using a bottle for urine collection. These specimens were centrifuged at 3,000 rpm for $5 \mathrm{~min}$. The supernatant was used to measure urinary protein and albumin levels.

Urinary protein levels were measured using a Bio-Rad Protein kit (Bio-Rad) at 10, 20 and 30 weeks of age. Urinary albumin levels were measured using a Nephrat kit (Exocell) at 20 and 30 weeks of age.

Glomerular filtration rate (GFR) and renal plasma flow $(R P F)$ : According to the method described by Sakamoto et al. [11], GFR and RPF were measured at 30 weeks of age. Four animals were assigned to each group. After rats were anesthetized with $50 \mathrm{mg} / \mathrm{kg}$ of thiopental sodium (Ravonal, Tanabe Pharmaceutical). A mixed solution of $1 \%$ inulin (Wako Pure Chemical Industry Co., Ltd.) through the cannulation tube inserted into the jugular vein, and $2.5 \%$ sodium p-aminohippurate (Nakaraitesk Co., Ltd.) was initially infused at a rate of $3.6 \mathrm{ml} / \mathrm{hr}$ for $20 \mathrm{~min}$, then at a rate of $1.2 \mathrm{ml} / \mathrm{hr}$ for $40 \mathrm{~min}$. Thereafter, the solution was infused at a rate of $1.2 \mathrm{ml} / \mathrm{hr}$, and urine and blood were collected from 3 times at 30-min intervals. Urinary and blood levels of inulin and sodium p-aminohippurate were measured. Based on these results, inulin clearance, $\mathrm{p}$-amino acid clearance and renal plasma flow were calculated.

Light microscopy: The OLETF rat and the LETO rat were used for the experiment. Four animals were assigned to each group. Kidney weights were determined, and quantitative analysis of glomerular lesions was performed with two sections of each kidney. Kidneys were fixed in $10 \%$ neutral-buffered formalin and embedded in paraffin, then cut into 2- to 4- $\mu \mathrm{m}$ sections for hematoxylin and eosin (H\&E) staining or periodic acid schiff (PAS) staining. Approximately two hundred glomeruli per animal were evaluated for the presence of glomerular lesion. For this purpose, a grid of squares was superimposed on the PASstained sections and all glomeruli were counted and evaluated for mesangial lesions, exudative lesions, and obsolesence in the glomeruli.

Ultrastructural study of glomerular basement membrane $(G B M)$ : The OLETF rat and the LETO rat were used for the experiment. Four animals were assigned to each group. Staining of glomerular anionic sites with polyethyleneimine $(\mathrm{PEI}$; molecular weight $=1,800$; Wako Pure Chemical Industries, Ltd., Osaka) was performed by a minor modification of the method described by Schurer $e t$ al. [13] and Sugimoto et al. [14]. Freshly sampled renal cortex was cut into $0.5 \mathrm{~mm}^{3}$ pieces and immersed in $0.5 \%$ PEI in physiological saline for $30 \mathrm{~min}$ at room temperature. After washing in 0.2 M cacodylate buffer (CB), pH 7.4, 400 mOsm, the blocks were reimmersed in the solution containing $2 \%$ phosphotungstic acid (PTA) and $0.1 \%$ glutaraldehyde (GA), $\mathrm{pH} 7.4,400 \mathrm{mOsm}$ at $4^{\circ} \mathrm{C}$ for $1 \mathrm{hr}$ to obtain insoluble precipitates of PEI bound to glomerular anionic sites. After washing 3 times for $10 \mathrm{~min}$ in $\mathrm{CB}$, the blocks were postfixed in $2 \%$ osmium tetraoxide in $\mathrm{CB}$ at $4^{\circ} \mathrm{C}$ for $2 \mathrm{hr}$. Then, blocks were dehydrated in graded ethanol and embedded in Quetol-812 (Nisshin EM, Tokyo). Ultrathin sections were cut then stained with uranyl acetate and lead citrate. Those stained with uranyl acetate and lead citrate were examined under a JEM 100 CXII transmission electron microscope (Hitachi, Ltd., Tokyo). The PEI solution was adjusted to $\mathrm{pH} 7.4$ with $\mathrm{HCl}$ and 400 mOsm with sucrose. A mixture of $2 \%$ PTA and $0.1 \%$ GA was prepared within $2 \mathrm{hr}$ before use (osmolality adjusted to 400 mOsm with sucrose and $\mathrm{pH}$ adjusted to 7.4 with concentrated $\mathrm{KOH}$ solution).

PEI were counted after specimens were photographed at 5,000-fold magnification under an electron microscope and the photographs were enlarged 4-fold (20,000-fold). Simultaneously, the GBM thickness was measured.

Statistical analysis: Actual values of body weight, protein intake, OGTT, urinary protein and urinary albumin were used. Data were analyzed statistically by repeated measures ANOVA. Factors included in the ANOVA model were treatment (protein-load), time point, and treatment (proteinload) and time interaction. Between subject variance and within subject variance were utilized as the error of statistical test. Significance of differences in mean values between the control group and the protein-loaded group for each strains were tested. With respect to GFR, RPF and kidney weight, actual values were compared between the control group and the protein-loaded group for each strain using $t$ test (paired). With respect to the number of PEI and glomerular basement membrane thickness, dual placement variance analysis was performed using group and section as factors in OLETF rats and LETO rats. Incidences of exudative lesions and mesangial lesions were compared between the control group and the protein-loaded group for each line using Wilcoxon's rank sum test (paired). For statistical analysis, a Statistical Analysis System (SAS, $\mathrm{R} 6,12$ ) was used. $\mathrm{P}<0.05$ was regarded as significant. Data are expressed as the mean \pm standard deviation (SD). 


\section{RESULTS}

Body weight: Changes in body weight in each group are shown in Fig. 1. Weight gain in the protein-loaded OLETF group was less marked than that in the control group at 9 or more weeks of age. At 29 weeks of age, when this experiment was completed, body weights were $661.8 \pm 40.7$ $\mathrm{g}$ in the protein-loaded group and $690.6 \pm 60.2 \mathrm{~g}$ in the control group. At 29 weeks of age, body weights were $484.7 \pm 13.9 \mathrm{~g}$ in the protein-loaded LETO group, $478.5 \pm$ $22.4 \mathrm{~g}$ in the control group, $336.6 \pm 12.6 \mathrm{~g}$ in the proteinloaded F344 group, $337.6 \pm 13.5 \mathrm{~g}$ in the control group, $420.3 \pm 11.9 \mathrm{~g}$ in the protein-loaded BN group and $388.4 \pm$ $11.9 \mathrm{~g}$ in the control group. OLETF and LETO group showed significant differences between protein-loaded groups and control groups.

Food intake and protein intake: Changes in food intake and protein intake in each group are shown in Fig. 2. Food intake in the protein-loaded OLETF group was significantly decreased compared to that in the control group immediately after this experiment was started. Protein intake in the protein-loaded OLETF group was increased by approximately $50 \%$ compared to that in the control. Among LETO, F344 and BN rats, protein intake in protein-loaded groups was increased by approximately $50 \%$ compared to that in control groups during the experiment period.

OGTT: Plasma glucose and insulin levels on OGTT at 26 weeks of age are shown in Fig. 3. In the protein-loaded OLETF group, the curve of plasma glucose was significantly decreased compared to that in the control group. In LETO, F344 and BN rats, plasma glucose levels did not significantly differ between protein-loaded groups and control groups. In both OLETF groups, the curve of plasma insulin was higher than those in other strains. However, there was no significant difference between the proteinloaded group and the control group. In LETO, F344 and BN rats, plasma insulin levels did not significantly differ between protein-loaded groups and control groups.

Urinary protein and albumin levels: Changes in urinary

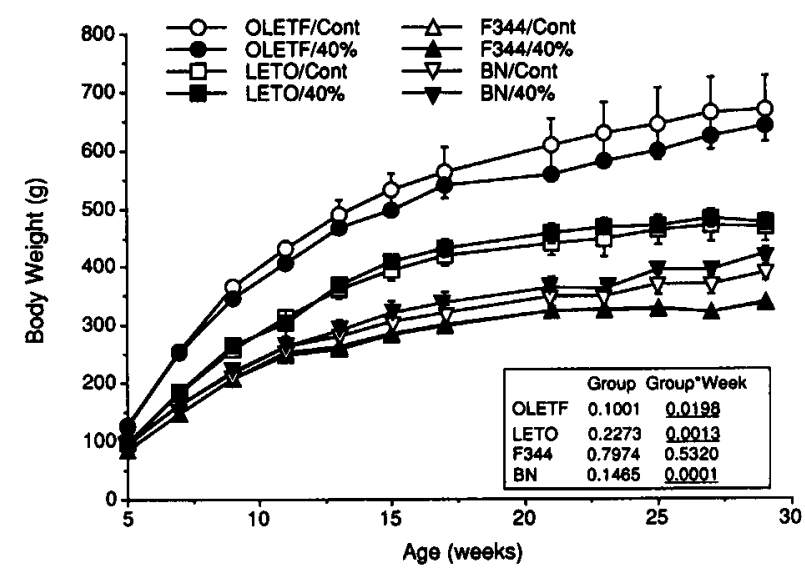

Fig. 1. Changes in body weight for each strains when a $40 \%$ protein diet was given between 5 and 30 weeks of age. Data were analyzed statistically by repeated measures ANOVA. Factors included in the ANOVA model were treatment (proteinload), time point, and treatment (protein-load) and time interaction. Values are expressed as the mean \pm standard deviation. The number of animals was 8 per group.
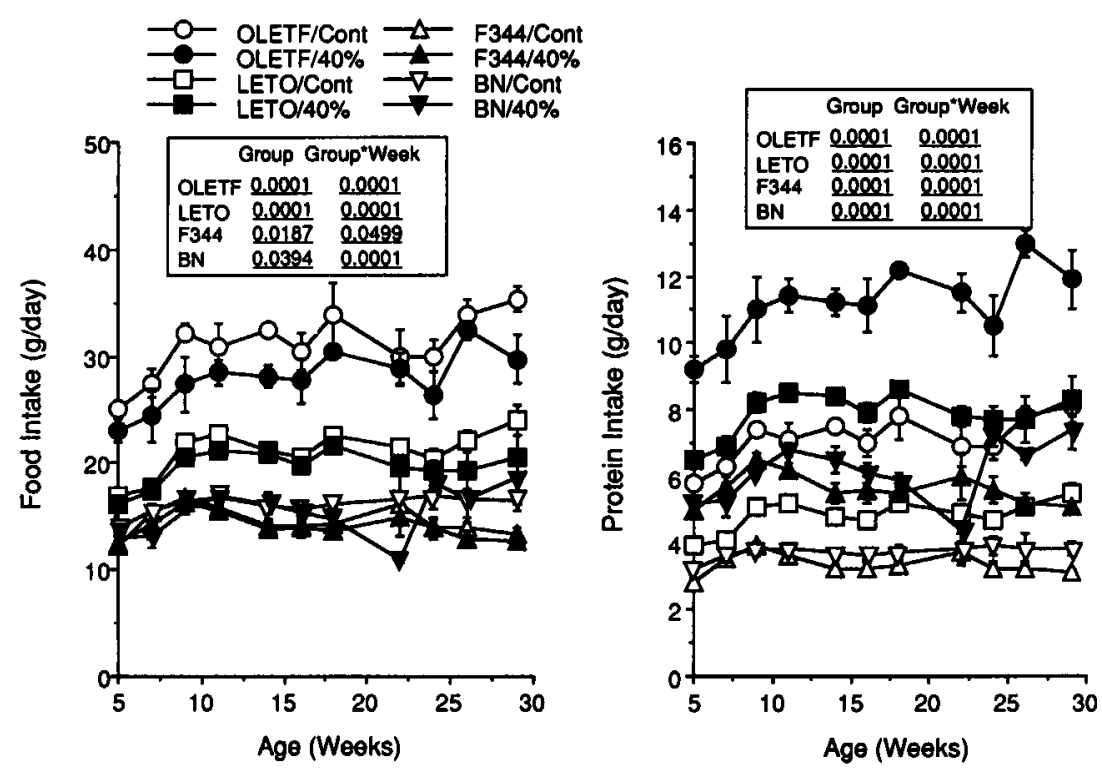

Fig. 2. Changes in food intake and protein intake for each strains when a $40 \%$ protein diet was given between 5 and 30 weeks of age. Data were analyzed statistically by repeated measures ANOVA. Factors included in the ANOVA model were treatment (protein-load), time point, and treatment (protein-load) and time interaction. Values are expressed as the mean \pm standard deviation. The number of animals was 8 per group. 

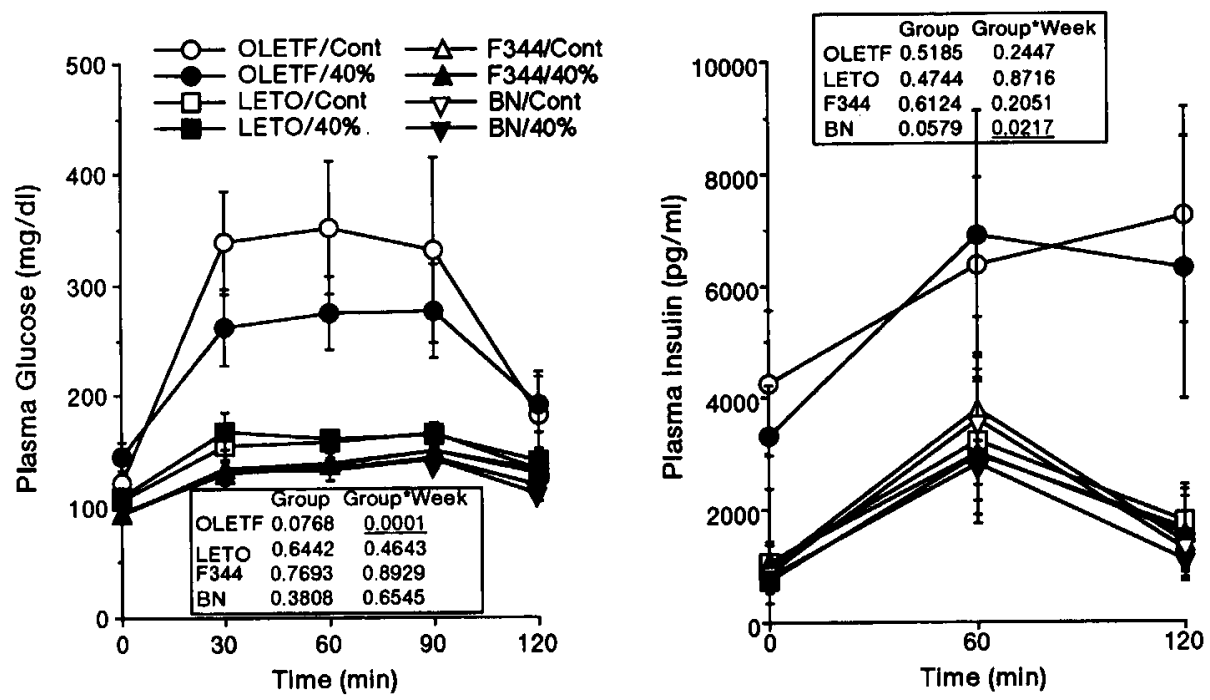

Fig. 3. Plasma glucose and insulin levels on OGTT at 26 weeks of age after a $40 \%$ protein diet was started at 5 weeks of age. Data were analyzed statistically by repeated measures ANOVA. Factors included in the ANOVA model were treatment (protein-load), time point, and treatment (proteinload) and time interaction. Values are expressed as the mean \pm standard deviation. The number of animals was 8 per group.
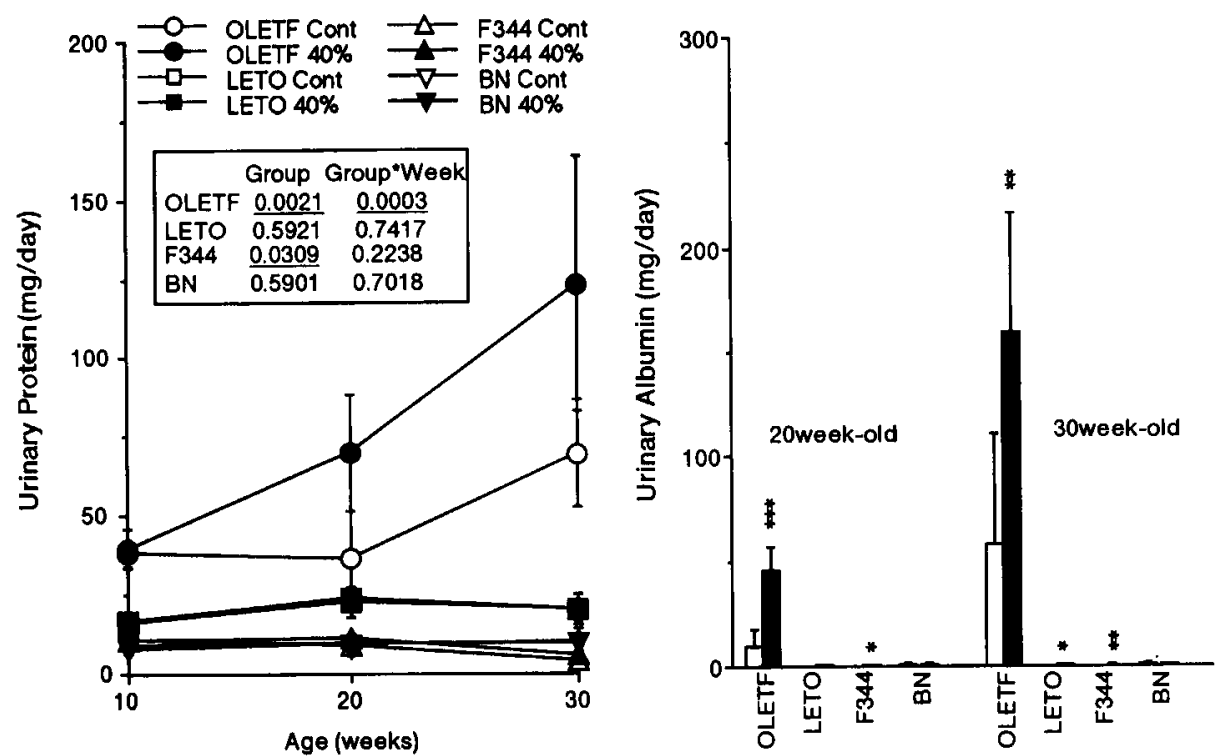

Fig. 4. Urinary protein and albumin levels when a $40 \%$ protein diet was given between 5 and 30 weeks of age. Concerning urinary protein levels, data were analyzed statistically by repeated measures ANOVA. Factors included in the ANOVA model were treatment (protein-load), time point, and treatment (protein-load) and time interaction. Concerning urinary albumin levels, $t$ test was used. On $t$ test, $\mathrm{P}<0.05$ or $\mathrm{P}<0.001$ was regarded as significant. Values are expressed as the mean \pm standard deviation. The number of animals was 8 per group.

protein and albumin levels in each group are shown in Fig. 4. In the protein-loaded OLETF group, the mean urinary protein level was similar to that in the control group at 10 weeks of age, but was markedly increased at 20 or more weeks of age. Among F344 rats, the mean urinary protein level in the protein-loaded group was significantly increased compared to that in the control group, although the increase was less marked than that in the OLETF rats. Among LETO and $\mathrm{BN}$ rats, there were no significant differences between protein-loaded groups and control groups. The mean urinary albumin level in the protein-loaded OLETF group was markedly increased compared to that in the control group at 
Table 2. GFR, RPF and Kidney weights when a $40 \%$ protein diet was given between 5 and 30 weeks of age

\begin{tabular}{|c|c|c|c|c|c|c|}
\hline & \multicolumn{3}{|c|}{ GFR } & \multicolumn{3}{|c|}{ RPF } \\
\hline & $\begin{array}{c}\text { GFR } \\
(\mathrm{m} l / \mathrm{min} .)\end{array}$ & $\begin{array}{c}\text { GFR/BW } \\
(\mathrm{m} l / \mathrm{min} . / \mathrm{g})\end{array}$ & $\begin{array}{l}\text { GFR/K.W. } \\
\text { (ml/min./g) }\end{array}$ & $\begin{array}{c}\mathrm{RPF} \\
(\mathrm{m} l / \mathrm{min} .)\end{array}$ & $\begin{array}{c}\text { RPF/BW } \\
(\mathrm{m} l / \mathrm{min} . / \mathrm{g})\end{array}$ & $\begin{array}{l}\text { RPF/K.W. } \\
\text { (ml/min./g) }\end{array}$ \\
\hline \multicolumn{7}{|l|}{ OLEFT } \\
\hline Control & $7.25 \pm 3.01$ & $0.011 \pm 0.004$ & $1.891 \pm 0.743$ & $8.75 \pm 4.68$ & $0.013 \pm 0.007$ & $2.284 \pm 1.193$ \\
\hline $40 \%$ protein diet & $6.90 \pm 2.59^{\text {N.S }}$ & $0.011 \pm 0.004^{\text {N.S. }}$ & $1.652 \pm 0.573^{\text {N.S. }}$ & $10.66 \pm 4.61^{\text {N.S. }}$ & $0.016 \pm 0.007^{\text {N.s. }}$ & $2.540 \pm 0.962^{\text {N.S. }}$ \\
\hline \multicolumn{7}{|l|}{ LETO } \\
\hline Control & $4.20 \pm 0.73$ & $0.009 \pm 0.001$ & $1.867 \pm 0.217$ & $8.73 \pm 1.05$ & $0.018 \pm 0.003$ & $3.894 \pm 0.446$ \\
\hline $40 \%$ protein diet & $5.18 \pm 2.08^{\text {N.S. }}$ & $0.010 \pm 0.004^{\text {N.S. }}$ & $1.811 \pm 0.975^{\text {N.S. }}$ & $9.71 \pm 2.25^{\text {N.S. }}$ & $0.019 \pm 0.004^{\text {N.S. }}$ & $3.343 \pm 1.230^{\text {N.S. }}$ \\
\hline \multicolumn{7}{|l|}{ F344 } \\
\hline Control & $2.39 \pm 0.70$ & $0.007 \pm 0.002$ & $1.315 \pm 0.365$ & $6.69 \pm 1.54$ & $0.020 \pm 0.004$ & $3.739 \pm 1.067$ \\
\hline $40 \%$ protein diet & $4.14 \pm 0.28 * *$ & $0.012 \pm 0.000 * *$ & $2.355 \pm 0.714^{*}$ & $9.13 \pm 2.07^{\text {N.S. }}$ & $0.027 \pm 0.005^{\mathrm{N} . S}$ & $5.047 \pm 1.120^{\mathrm{N} . S}$ \\
\hline \multicolumn{7}{|l|}{$\mathrm{BN}$} \\
\hline Control & $2.65 \pm 0.38$ & $0.007 \pm 0.001$ & $1.371 \pm 0.227$ & $5.85 \pm 0.68$ & $0.015 \pm 0.002$ & $3.027 \pm 0.409$ \\
\hline $40 \%$ protein diet & $2.98 \pm 0.38^{\mathrm{N} . \mathrm{S}}$ & $0.007 \pm 0.001^{\mathrm{N} . S}$ & $1.228 \pm 0.188^{\text {N.S. }}$ & $6.96 \pm 2.86^{\text {N.s. }}$ & $0.016 \pm 0.006^{\mathrm{N} . S}$ & $2.869 \pm 1.195^{\text {N.S. }}$ \\
\hline
\end{tabular}

Data are given as mean $\pm \mathrm{SD}, \mathrm{N}=4$. Significance was tested using $t$ test. $\mathrm{P}<0.05$ was regarded as significant, $* ; \mathrm{p}<0.05, * * ; \mathrm{p}<0.01, \mathrm{~N} . \mathrm{S}$.; Not significant. BW; Body weight, K.W.; Kidney weight. GFR; Glomerular filtration rate. RPF; Renal plasma flow.

Table 3. Number of polyethyleneimine (PEI) width of glomerular basement membrane incidence of glomerular lesions and kidney weight when a $40 \%$ protein diet was given between 5 and 30 weeks of age

\begin{tabular}{|c|c|c|c|c|c|c|c|}
\hline & \multicolumn{2}{|c|}{ Glomerular basement membrane } & \multicolumn{3}{|c|}{ Glomerular lesions } & \multicolumn{2}{|c|}{ Kidney weight } \\
\hline & $\begin{array}{l}\mathrm{PEI}^{\mathrm{b})} \\
\mathrm{N}=4\end{array}$ & $\begin{array}{c}\text { No. of } \\
\text { Width of } \mathrm{GMB}^{\mathrm{b})} \\
(\mathrm{nm}) \mathrm{N}=4\end{array}$ & $\begin{array}{l}\text { Mesangial } \\
\text { Glomerulic), }^{\mathrm{N}} \text {, }\end{array}$ & $\begin{array}{c}\text { Exudative } \\
\text { lesion }(\%)^{\mathrm{c})} \text {, } \\
\mathrm{N}=4\end{array}$ & $\begin{array}{l}\text { Lesion }(\%)^{\mathrm{c})} \\
\quad \mathrm{N}=4\end{array}$ & $\begin{array}{c}\text { Relative } \\
\text { Wet weight }{ }^{\mathrm{d})} \\
\text { (g) N=8 }\end{array}$ & $\begin{array}{l}\text { weight }(\mathrm{g} \%)^{\mathrm{d})} \text {, } \\
\mathrm{N}=8\end{array}$ \\
\hline \multicolumn{8}{|l|}{ OLETF } \\
\hline Control & $8.60^{\mathrm{a})} \pm 1.03^{* * *}$ & $5.86^{\mathrm{a})} \pm 0.68^{* * *}$ & $197.3^{\mathrm{a})} \pm 27.0^{\text {N.S. }}$ & $31.1^{\text {a) }} \pm 5.9^{*}$ & $1.2^{\mathrm{a})} \pm 1.1^{\mathrm{N} . S}$ & $3.57^{\mathrm{a})} \pm 0.33^{* * *}($ & $0.52^{\mathrm{a})} \pm 0.05^{* * *}$ \\
\hline $40 \%$ protein diet & $7.18 \pm 1.72 *$ & $6.34 \pm 0.88^{\text {N.S. }}$ & $200.8 \pm 20.6^{\text {N.S. }}$ & $26.6 \pm 5.1^{\text {N.S. }}$ & $4.8 \pm 1.7 *$ & $3.88 \pm 0.43^{\text {N.S. }}$ & $0.58 \pm 0.05^{* *}$ \\
\hline \multicolumn{8}{|l|}{ LETO } \\
\hline Control & $11.38 \pm 1.23$ & $4.33 \pm 0.53$ & $182.0 \pm 16.7$ & $1.8 \pm 0.9$ & 0 & $2.20 \pm 0.13$ & $0.46 \pm 0.01$ \\
\hline $40 \%$ protein diet & $11.36 \pm 1.18^{\text {N.S. }}$ & $4.33 \pm 0.39^{\text {N.S. }}$ & $186.0 \pm 11.9^{\text {N.S. }}$ & $1.8 \pm 0.5^{\text {N.S. }}$ & 0 & $2.66 \pm 0.57^{\text {N.S. }}$ & $0.54 \pm 0.09^{\text {N.S. }}$ \\
\hline
\end{tabular}

Data are given as mean \pm SD.

a) OLETF control vs LETO control.

b) Dual placement variance analysis was performed using group and section as factors. $\mathrm{P}<0.05$ or $\mathrm{P}<0.001$ was regarded.

c) Significance was tested using Wilcoxon's rank sum test. $\mathrm{P}<0.05$ was regarded as significant.

d) Significance was tested using $t$ test. $\mathrm{P}<0.01$ was regarded as significant.

$* ; \mathrm{p}<0.05, * * ; \mathrm{p}<0.01, * * * ; \mathrm{p}<0.001$, N.S.; Not Significant.

20 and 30 weeks of age. Among LETO and F344 rats, mean urinary albumin levels in protein-loaded groups were significantly higher than those in the control groups. However, the rate of increase was smaller than that in OLETF rats. Among BN rats, there was no significant difference between the protein-loaded group and the control group.

Glomerular filtration rate (GFR) and renal plasma flow $(R P F)$ : GFR and RPF in each group are shown in Table 2. GFR in both OLETF groups were higher than those in other strains. However, there was no significant difference between the protein-loaded group and the control group. Neither LETO nor BN rats showed any significant differences between protein-loaded groups and control groups. However, in the protein-loaded F344 group, GFR was significantly increased compared to that in the control group. Among all strains, RPF in protein-loaded groups was slightly higher than that in control groups, although there were no significant differences.

Kidney weight: Kidney weights in each group are shown in Table 3. In this experiment, kidney weights were $2.2 \mathrm{~g}$ $(0.46 \mathrm{~g} \%$ body weight $)$ in the control LETO group and 3.57 $\mathrm{g}(0.52 \mathrm{~g} \%)$ in the control OLETF group. In control OLETF group, kidney weight was markedly increased compared to that in control LETO group. In addition, in the proteinloaded OLETF group, kidney weight (3.88 g, $0.58 \mathrm{~g} \%$ ) was more markedly increased compared to that in the control group (3.57 g $0.52 \mathrm{~g} \%)$.

Light microscopy: Light micrograph of glomerulus in control OLETF (A), protein-loaded OLETF (B) and control LETO (C), protein-loaded LETO (D) rat at 30 weeks of age are shown in Fig. 5, and Table 3. In both OLETF groups, glomerular hypertrophy, exudative lesions with fibrin-cap and dilatation of the mesangial area related to proliferation of mesangial cells in the kidney glomerulus were observed. In the control OLETF group, exudative lesions comprised 


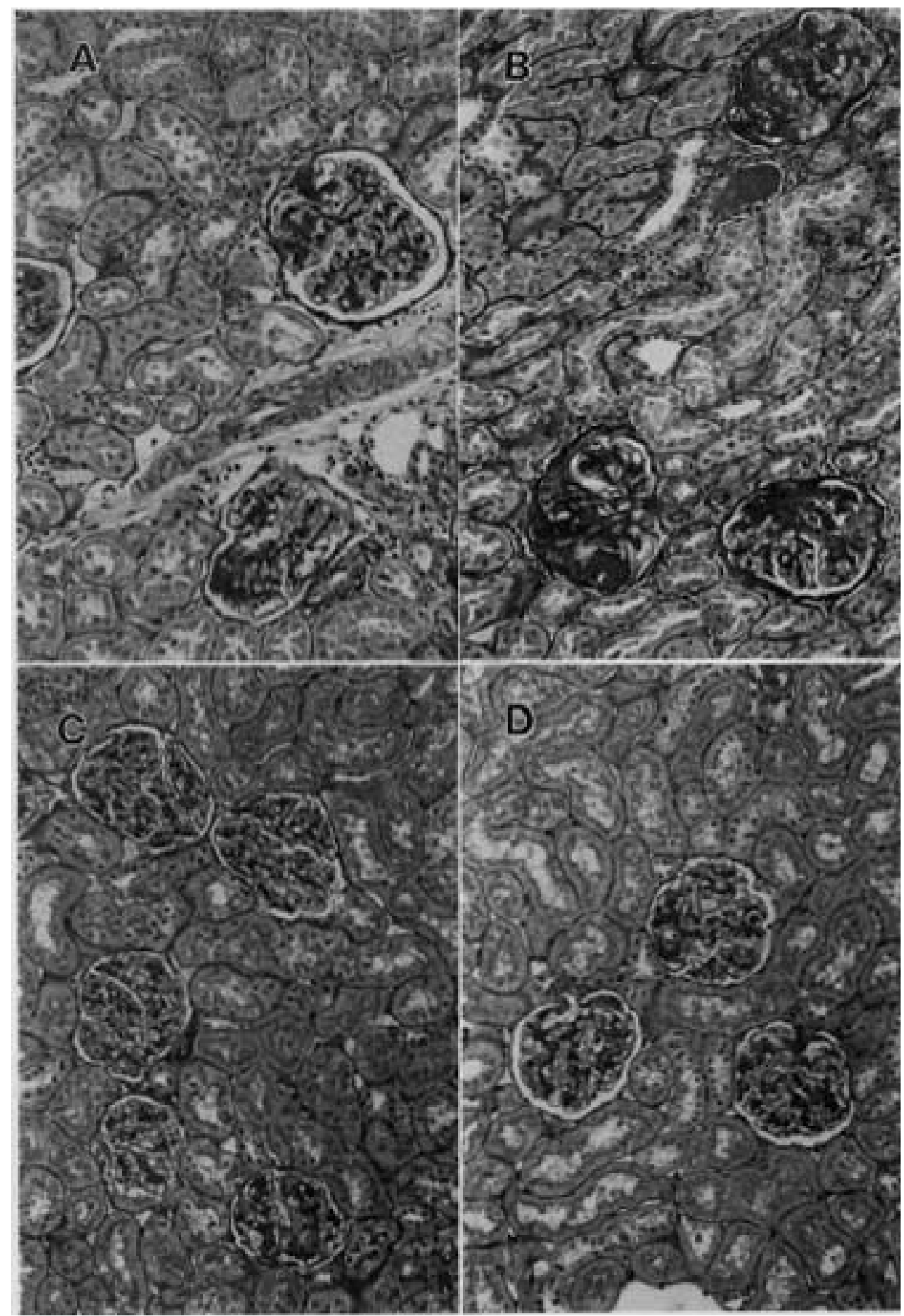

Fig. 5. Light micrograph of glomerulus in control OLETF (A), protein-loaded OLETF(B) and control LETO (C), protein-loaded LETO (D) rat at 30 weeks of age (PAS staining $50 \times$ ). In both OLETF groups, glomerular hypertrophy, exudative lesions with fibrin-cap in the kidney glomerulus were observed. Glomerular hypertrophy in the control OLETF group was more marked than that in the control LETO group. 


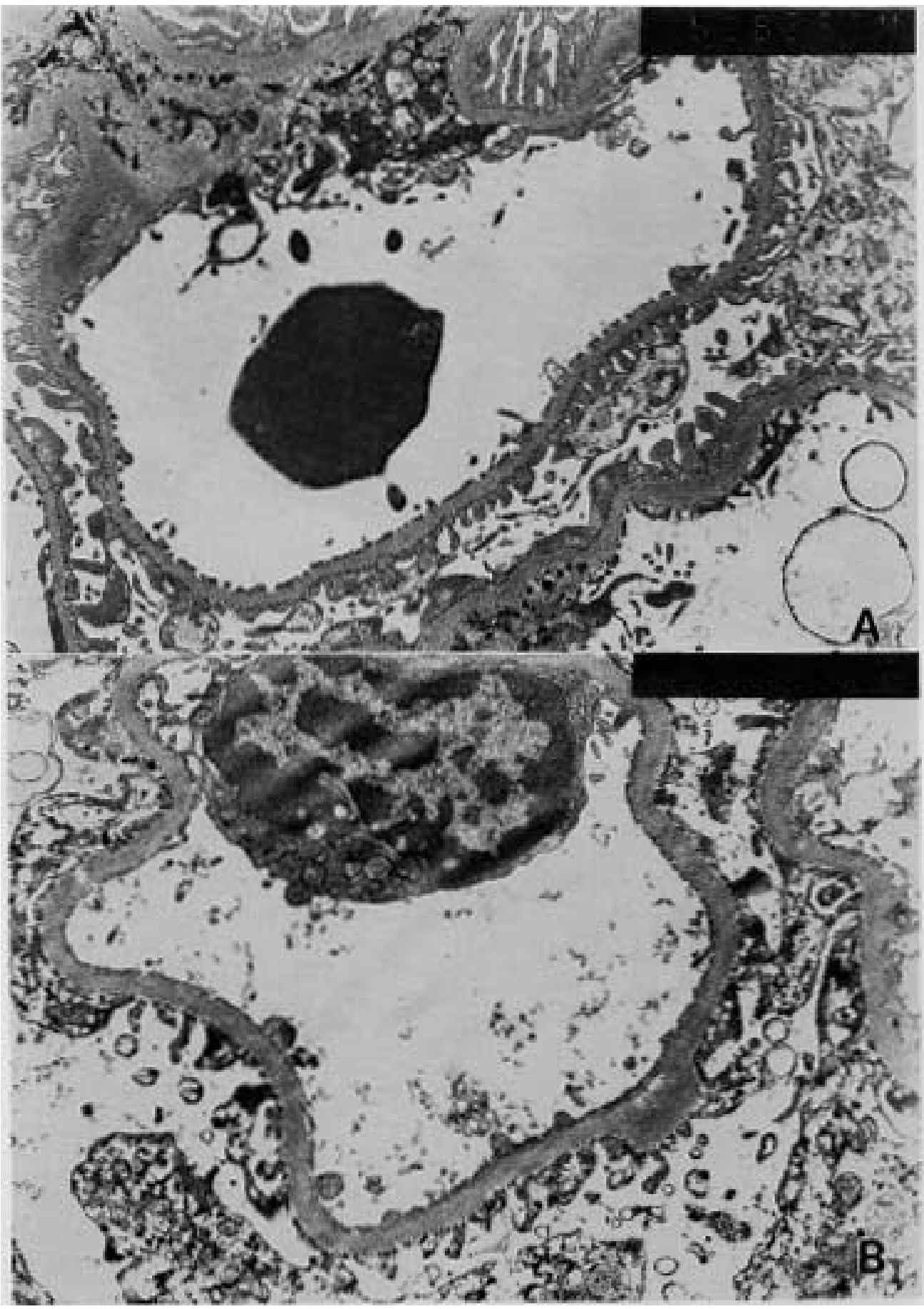

Fig. 6. Electron micrograph of glomerular basement membrane(GBM) with PEI staining in OLETF and LETO rats at 30 weeks of age. A) control LETO rat, $(5,000 \times)$ B) control OLETF rat $(5,000 \times)$, C)control OLETF rat $(10,000 \times)$, D) protein-loaded OLETF rat $(10,000 \times)$. The number of PEI in the control OLETF group was decreased compared to that in control LETO rats. GBM thickness in the control OLETF group was larger than that in control LETO rats. Foot processes in control and protein-loaded LETO groups showed a normal height and interval on the basement membrane. However, in control and protein-loaded groups of OLETF rats, both the height and interval of foot processes were irregular and fused. 


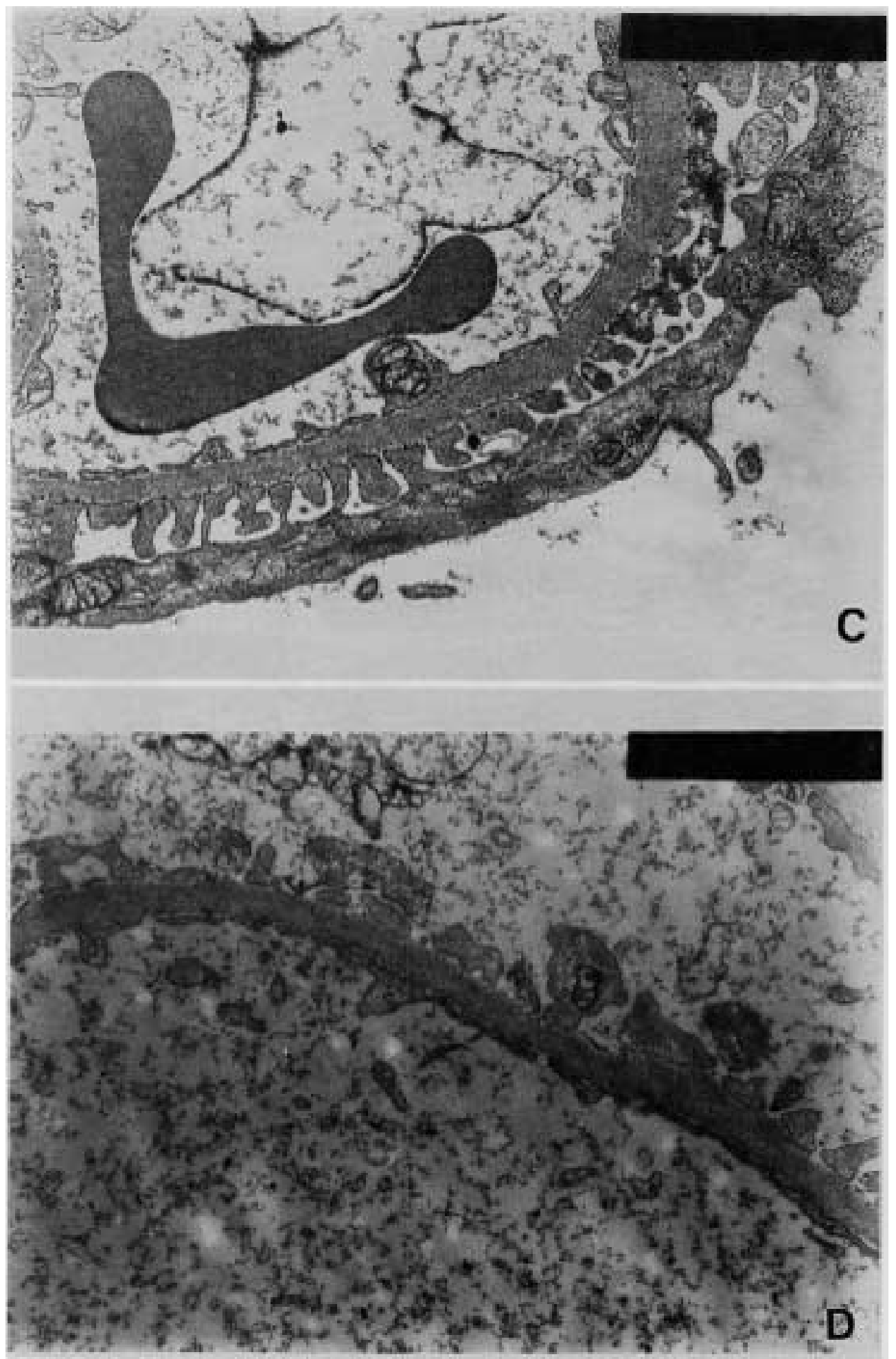

$1.2 \pm 1.1 \%$ of the entire glomerulus. In the protein-loaded group, the percentage was significantly increased to $4.8 \pm$ $1.7 \%$. Expansion in the mesangial area were $31.1 \pm 5.9 \%$ in the control group and $26.6 \pm 5.1 \%$ in the protein-loaded group. There was no significant difference. Furthermore, glomerular hypertrophy in the protein-loaded OLETF group was more marked than that in the control group. Among the remaining 3 strains, neither control groups nor proteinloaded groups showed any marked lesions.

Electron microscopy: Electron micrograph of glomerular 
basement membrane (GBM) with PEI staining in OLETF and LETO rats at 30 weeks of age are shown in Fig. 6, Table 3. In the protein-loaded OLETF group, the number of PEI was significantly decreased compared to that in the control group. However, among LETO rats, there was no significant difference between the protein-loaded group and the control group. The number of PEI in the control OLETF group was significantly decreased compared to that in LETO rats. GBM thickness in the control OLETF group was significantly larger than that in control LETO rats. However, there was no significant difference between the protein-loaded group and the control group. Foot processes in control and protein-loaded LETO groups showed a normal height and interval on the basement membrane. However, in control and protein-loaded groups of OLETF rats, both the height and interval of foot processes were irregular and fused. In the protein-loaded OLETF group, rupture of the basement membrane was observed, although the incidence was low.

\section{DISCUSSION}

Protein intake may influence deterioration of nephropathy in OLETF rats, we conducted protein loading in OLETF rats to examine deterioration of nephropathy and clarify the pathogenesis.

The glomerular lesions found in OLETF rats, similar to those in human diabetic nephropathy are exudative lesions characterized by fibrin cap, capsular drop and aneurysmal dilatation of intraglomerular vessels. However, the pathogenesis of diabetic nephropathy in OLETF rats demonstrating these findings remains to be clarified.

After protein loading in OLETF rats, urinary protein and albumin levels, which are indices of diabetic nephropathy, were increased. In LETO, F344 and BN rats without diabetes, there were no marked changes in urinary protein or albumin levels. The internal and external hyaline layers of the GBM function as a charge barrier via heparan sulfate, and inhibits the passage of negatively charged substances such as albumin [6]. However, it has been reported that heparan sulfate levels are decreased under diabetic conditions, destroying the charge barrier and enhancing the permeability of the GBM [10]. In this experiment, protein loading in OLETF rats significantly decreased the number of PEI on the GBM, suggesting destruction of the charge barrier. On electron microscopy, foot processes in control and protein-loaded groups of LETO showed a normal height and interval on the GBM. However, foot processes in OLETF rats were irregularly arranged and fused. Therefore, it is suggested that the pathogenesis of diabetic nephropathy in OLETF rats involve enhancement of permeability related to destruction of the charge barrier.

In humans, it has been reported that GFR and RPF are increased after intravenous administration of amino acid, a component of protein [15]. Concerning the mechanism involved in this finding, it is speculated that protein loading increases blood amino acid levels, increasing vasodilative prostaglandin (PG) levels and elevating GFR and RPF, since pretreatment with a PG production-inhibiting agent, indomethacin, inhibits increases in GFR and RPF even when amino acid is administered [3]. In rats, it has also been reported that protein loading increases GFR [16]. These increases in GFR and intraglomerular pressure are considered to promote formation of the mesangial matrix [1]. Based on these studies, we speculated that protein loading might cause increases in GFR and intraglomerular pressure, exacerbating diabetic nephropathy in OLETF rats. However, protein loading in OLETF rats did not cause any changes in GFR or RPF. This may be because GFR was measured at 30 weeks of age in this study; the urinary protein level in the control OLETF group was also increased at this age, suggesting that GFR had already increased. Therefore, there may not have been any differences between the protein-loaded group and the control group.

In patients with diabetic nephropathy, the initial physiological change is glomerular hyperfiltration, while the initial morphological change is glomerular hypertrophy. Mogenson [7] initially examined glomerular hyperfiltration and renal hypertrophy in-patients with early-stage diabetic nephropathy, and found increases in kidney weight inpatients with IDDM. They indicated that increases in the GFR during the initial phase correlated with glomerular volume and glomerular loop area in-patients with IDDM and that mesangial volume gradually increased with GFR. In this experiment, in both OLETF groups, kidney weight was markedly increased compared to that in both LETO rats. In addition, in the protein-loaded OLETF group, kidney weight was more markedly increased compared to that in the control group, suggesting that renal function be enhanced during the early stage in the protein-loaded OLETF group. In OLETF rats, glomerular hypertrophy, expansion in the mesangial area related to increased mesangial matrix, and renal hypertrophy was noted together with albuminuria during the early stage [2].

A body weight increase in protein-loaded OLETF group was suppressed compared with the control OLETF group. The decrease in food intake of the OLETF rat protein load group is raised as this reason. In addition in this experiment, plasma glucose curve in the protein-loaded OLETF group by OGTT at 26 weeks of age was decreased compared to those in the control OLETF group. Despite this finding, urinary protein levels and glomerular morphological changes exacerbated. In a word, A diabetic nephropathy did deterioration though the diabetic improved in protein-load OLETF group like this. Many studies have indicated that the state of blood sugar control is closely involved in the onset of diabetic nephropathy. However, the experiment result at this time became a conflicting result. Therefore, the protein intake was proven to be more important than the blood control from the experiment as for a risk factor of a diabetic nephropathy.

In this experiment, protein loading in OLETF rats caused deterioration of diabetic nephropathy at 30 weeks of age. Therefore, it was shown that protein intake than blood sugar 
control was important factors for deterioration of diabetic nephropathy in OLETF rats. Furthermore, the mechanism by which nephropathy deteriorates may involve enhancement of renal function and increased permeability related to destruction of the charge barrier of the GBM.

\section{REFERENCES}

1. Anderson, S. and Vora, J.P. 1995. Current concept of renal hemodynamics in diabetes. J. Diabetes Complicat. 9: 304307.

2. Fukuzawa, Y., Watanabe, Y., Inaguma, D. and Hotta, N. 1996. Evaluation of glomerular lesion and abnormal urinary findings in OLETF rats resulting from a long-term diabetic state. J. Lab. Clin. Med. 128: 568-578.

3. Hirschberg, R.R., Zipser, R.D., Slomowitz, L.A. et al. 1988. Glucagon and prostaglandins are mediators of amino acidinduced rise in renal hemodynamics. Kidney Int. 33: 1147-1155.

4. Ishida, K., Mizuno, A., Min, Z., Sano, T. and Shima, K. 1995. Which is the primary etiologic event in Otsuka LongEvans Tokushima Fatty rats, a model of spontaneous non-insulin-dependent diabetes mellitus, insulin resistance, or impaired insulin secretion? Metabolism 44: 940-945.

5. Kawano, K., Hirashima, T., Mori, S., Saitoh, Y., Kurosumi, M. and Natori, T. 1992. Spontaneous long-term hyperglycemic rat with diabetic complications Otsuka Long-Evans Tokushima Fatty (OLETF) strain. Diabetes 41: 1422-1428.

6. Kanwar, Y.S., Veits, A., Kimma, J.H. and Jakubowski, M.L.1984.Characterization of heparan sulfate proteoglycan of glomerular basement membranes. Proc. Natl. Acad. Sci. U.S.A. 81: 762.

7. Mogenson, C.E.1982. Diabetic mellitus and the kidney. Kidney Int. 21: 673-675.

8. Mori, S., Kawano, K. and Hirashima, T. 1996. Study on progress of diabetes induced sucrose-load in OLETF rats. 13th Japan Assoc. Anim. Diabetes Res. (in Japanese)

9. Mori, S., Kawano, K. and Hirashima, T. 1966. Study on progress of diabetes and diabetic nephropathy induced sucrose-load in OLETF rats. J. Jpn. Diabetes Soc. 39: (Suppl. 1) (2L11) (in Japanese).

10. Rosenzweig, L.J. and Kanwar, Y.S. 1982. Removal of sulfated (heparan sulfate) of nonsulfate (hyaluronic acid) glycosaminoglycans results in increased permeability of the glomerular basement membrane to ${ }^{125}$ I-BSA. Lab. Invest. 47 : 177.

11. Sakamoto, K., Kikkawa, R., Haneda M. et al. 1995. Prevention of glomerular hyperfiltration in rats with streptozotocininduced diabetes by an atrial natriuretic peptide receptor antagonist. Diabetologia 38: 536-542.

12. Sato, T., Asahi, Y., Toide, K. and Nakayama, N. 1995. Insulin resistance in skeletal muscle of the male Otsuka Long-Evans Tokushima Fatty rat, a new model of NIDDM. Diabetologia 38: 1033--1041.

13. Schurer, J.W., Kalicharan, D., Hoedemacker, P.H.J. and Molenaar, I. 1978. The use of polyethyleneimine for determination of anionic sites in basement membranes and collagen fibrils. J Histochem Cytochem 26: 688-689.

14. Sugimoto, J., Wasaki, M., Shirota, K. et al. 1994. Alterations in glomerular anionic sites in canine anti-glomerular basement membrane nephritis with onset of severe proteinuria. Toxicol. Pathol. 22: 316-323.

15. Tuttle, K.R., Bruton, J.L., Perusek, M.C. et al. 1991. Effect of strict glycemic control on renal hemodynamic response to amino acids and renal enlargement in insulin-dependent diabetes mellitus. New Engl. J. Med. 324: 1626-1632.

16. Zatz, R., Meyer, T.W., Rennke, H.G. et al. 1985. Predominance of hemodynamic rather than metabolic factors in the pathogenesis of diabetic glomerulopathy. Proc. Natl.Acad. Sci. U.S.A. 82: 5963--5967. 